\title{
Effect of Magnetic Flux Density on the Population of Salmonella Species in River Njoro Water
}

\author{
Thirika Anne Mwende ${ }^{1, *}$, Onyango Lawrence Omondi ${ }^{2}$ \\ ${ }^{1}$ Physics Department, Egerton University, Nakuru, Kenya \\ ${ }^{2}$ Mathematics Department, Egerton University, Nakuru, Kenya \\ *Corresponding author: annethirika@gmail.com
}

\begin{abstract}
In this study, the experimental results of the concentration of Salmonella species in water exposed to magnetic flux density are presented. Water samples were collected from River Njoro, Nakuru County, Kenya. The initial Salmonella species counts for the samples were obtained using Membrane Filtration techniques. The samples were then exposed to different magnetic flux densities $(2 \mathrm{mT}, 6 \mathrm{mT}$ and $10 \mathrm{mT})$ at time intervals of 6 hours and 18 hours for each magnetic flux. Membrane filtration was also done after magnetic treatment of the samples. The data obtained was photographed and presented in tables and bar graphs. The maximum disinfection efficiency was $77 \%$ for bacteria exposed to a magnetic flux of $10 \mathrm{mT}$ for 6 hours. This study proved that magnetic field can be used as inhibitory factor against the Salmonella species.
\end{abstract}

Keywords: salmonella, magnetic flux densities, membrane filtration, magnetic field

Cite This Article: Thirika Anne Mwende, and Onyango Lawrence Omondi, "Effect of Magnetic Flux Density on the Population of Salmonella Species in River Njoro Water." International Journal of Physics, vol. 5, no. 4 (2017): 135-140. doi: 10.12691/ijp-5-4-5.

\section{Introduction}

For centuries, the availability of a safe drinking water has been a concern for mankind all over the world. According to the United Nations Development programme (UNDP), 780 million people lack access to clean drinking water that is approximately one in nine people in any population sample [1]. Moreover, World Health Organization [2] reported that over $41 \%$ of Kenyans do not have access to clean water and rely directly on rivers as the main source of water [3]. Many rivers are reportedly prone to high bacterial contamination due to heightened ecological activities and may therefore be unsuitable for human consumption when untreated [4].

Study has indicated that the microbial quality of the River Njoro water sources is poor and unacceptable for human consumption due to consistent increase in total and fecal coliforms and also due to pathogenic loading downstream [5]. This water is contaminated with pathogens which lead to widespread of acute and chronic illnesses which are major cause of death and misery. In 2012, World Health Organization indicated in their report that about 3.41 million people die each year from water, sanitation and hygiene-related causes [2]. The water and sanitation crisis claims more lives through disease than any war claims through guns [3].

In latest years, several studies have been performed to verify direct effects exerted by extremely low-frequency (ELF) electromagnetic fields (EMFs) on cell functions. In particular, it has been demonstrated that ELF-EMF can negatively $[6,7,8,9]$ or positively $[10,11]$ affect functional parameters (cell growth and viability) of a cell. The effects of magnetic fields on cells are thus not fully understood since some of the results have been inconsistent and have in other cases contradicted each other. The aim of this study was thus to evaluate the effect of magnetic flux density on the population of Salmonella species in water.

\section{Location of the Study Area}

River Njoro (Figure 1) is located within the Kenyan Rift Valley in Nakuru County and is approximately 60 kilometers $(\mathrm{km})$ in length (Jenkins et al., 2004). It is a high altitude stream with its source at the eastern segment of Mau Hills around $2700 \mathrm{~m}$ a. s. 1 and terminates in Lake Nakuru. Its geographical location is $\mathrm{S} 00^{\circ} 34.588^{\prime}$; ${\mathrm{E} 035^{\circ}}^{\circ} 54.684^{\prime}$ [12]. It is the major source of water for domestic purposes (drinking, washing, cooking and bathing), industrial and agricultural use for the surrounding community including Nakuru town, Njoro town, Kenya Agricultural and Livestock Research Organisation (KALRO) and Njoro Canning factory. This location is shown in Figure1 below.

\section{Sample Collection, Experiment Setup and Analysis}

Water samples were collected at Njoro Bridge, along River Njoro, (Figure 1). Sampling was done weekly for five months using sterilized water sample bottles $(250 \mathrm{ml})$. Magnetic treatment of the samples was done in the Physics Laboratory of Egerton University. Microbiological parameters and spectrophotometry were evaluated from Water Resource Management Authority (WRMA) laboratories in Nakuru. 


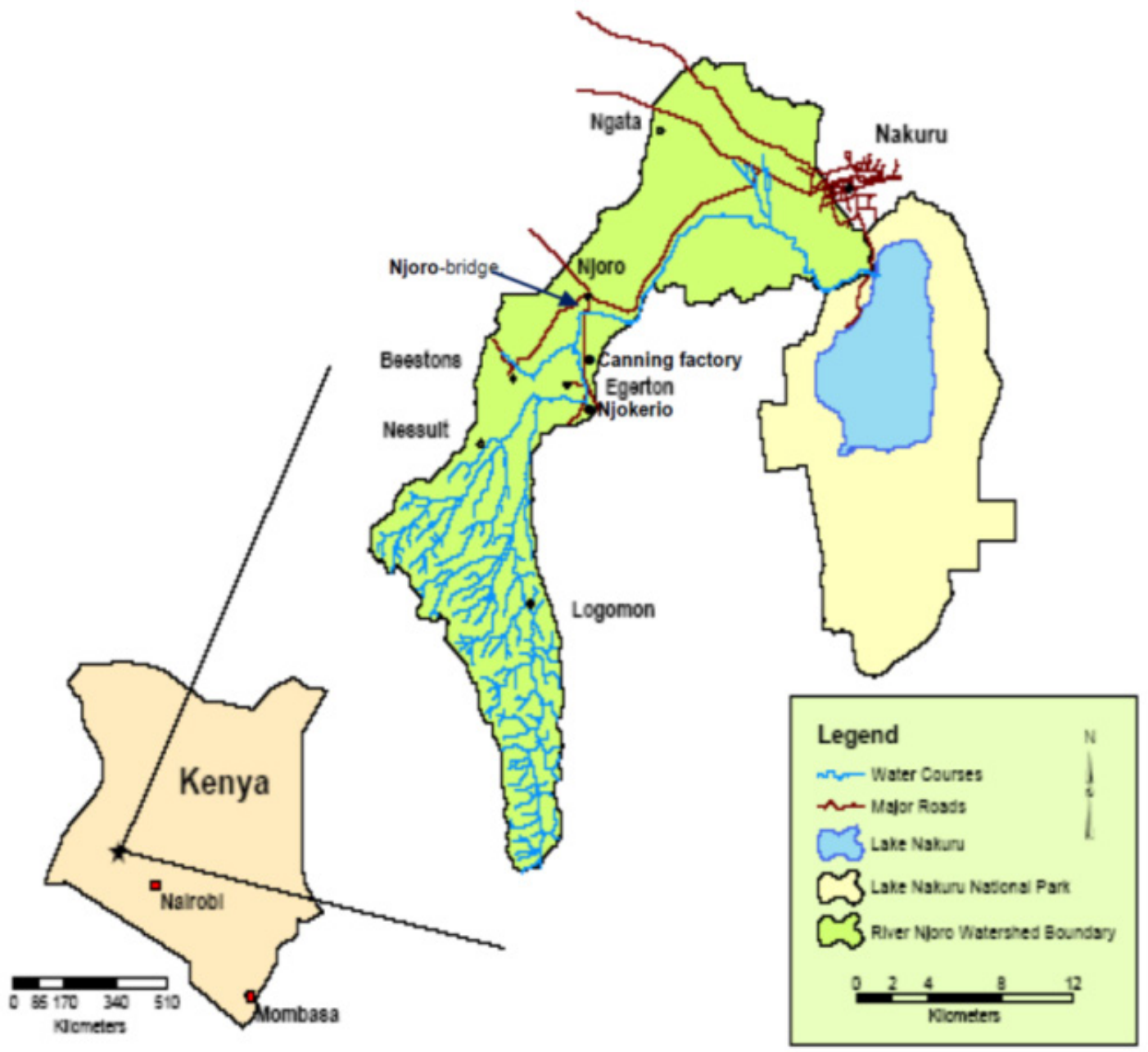

Figure 1. Map of River Njoro from source in Mau Forest to Lake Nakuru

Analysis was done within 0-24 hours after sampling to avoid changes of the bacteria count due to growth or die off [13]. Analysis involved the use of membrane filtration (MF) procedures to estimate the initial number of Salmonella species present in the water samples.

\subsection{Membrane Filtration}

Membrane filtration was done according to American Public Health Association (APHA) Standard Methods [14]. Appropriate dilutions of the water sample were done using distilled water. $100 \mathrm{ml}$ of the sample was aseptically filtered through a membrane filter $(47 \mathrm{~mm}$ diameter, $0.45 \mu \mathrm{m}$ pore size) on a filtration unit.

The filter was then taken off using a pair of sterilized forceps and placed on the surface of the corresponding culture media. Colony forming units (CFU) per $100 \mathrm{ml}$ of the sample were calculated as described in the United States Department of Agriculture, Food Safety and Inspection Services manual [15].

To isolate Salmonella species, the filters were placed on Salmonella Shigella agar and incubated at 370C for 24 hours. Black colonies on the plate indicated the presence of Salmonella species and their numbers were also expressed as CFU's /100ml.

The water samples were subjected to three different magnetic flux densities $(2 \mathrm{mT}, 6 \mathrm{mT}$ and $10 \mathrm{mT})$ treatments in addition to control which was not subjected to a magnetic field. For each magnetic field, the samples were exposed for 2 time periods (6hours and 18 hours). The magnetic B field was produced by Helmholtz coils which were connected to a power supply producing a direct current see, Plate 1. An ammeter was also connected in series with the power supply to measure the amount of current passing through the Helmholtz coils.

Magnetic flux densities were varied using different currents. A teslameter was used to measure the amount of the magnetic B-field produced.

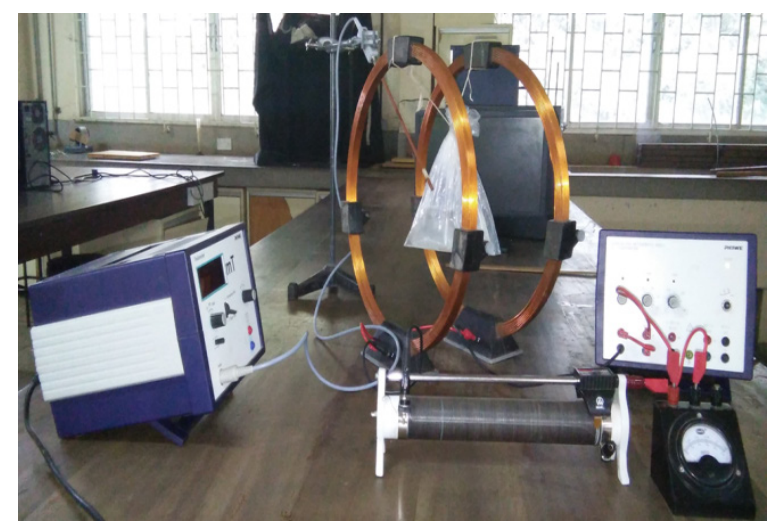

Plate 1. Experimental setup for water samples magnetic B-field application 


\section{Data Analysis}

All experiments were replicated three times and the statistical significance of each difference observed among the mean values was determined by standard error analysis. All mean data were statistically analysed with a general linear model procedure of statistical analysis system. The Statistical analysis was done using the Statistical Package for Social Sciences (SPSS) software (Version 17.5). Pearson correlation analysis was carried out to determine the relationship between magnetic field intensity and the bacterial count. One-way ANOVA with $95 \%$ confidence level was done to compare the effect of the magnetic field intensities with the Salmonella species count.

\section{Results and Discussion}

\subsection{Microbiological Parameter}

This study investigated the biological effect of magnetic fields, as a component of the non-ionizing radiations, on a unicellular system. Pathogenic microorganism, especially S.typhi was chosen as it is the main cause of typhoid fever. The bacterial cultures were exposed to different MFD $\left(2 \mathrm{mT}, 6 \mathrm{mT}\right.$ and $10 \mathrm{mT}$ ) at $25^{\circ} \mathrm{C}$. The duration of exposure was 6 hours and 18 hours which were within the range of the bacterial logarithmic growth phase.

\subsection{Effect of MFD on Salmonella Species}

Black colonies on the surface of the SS agar showed presence of Salmonella species. Plates 2 and 3 (a, b, c, d) show densities of Salmonella species without B-field exposure (control), under a B-field exposure of $2 \mathrm{mT}$, of 6 $\mathrm{mT}$ and of $10 \mathrm{mT}$ for 6 , and 18 hours respectively. The results in plate 2 show that there is a significant decrease in the number of CFU's with increasing magnetic field after 6 hours of exposure.

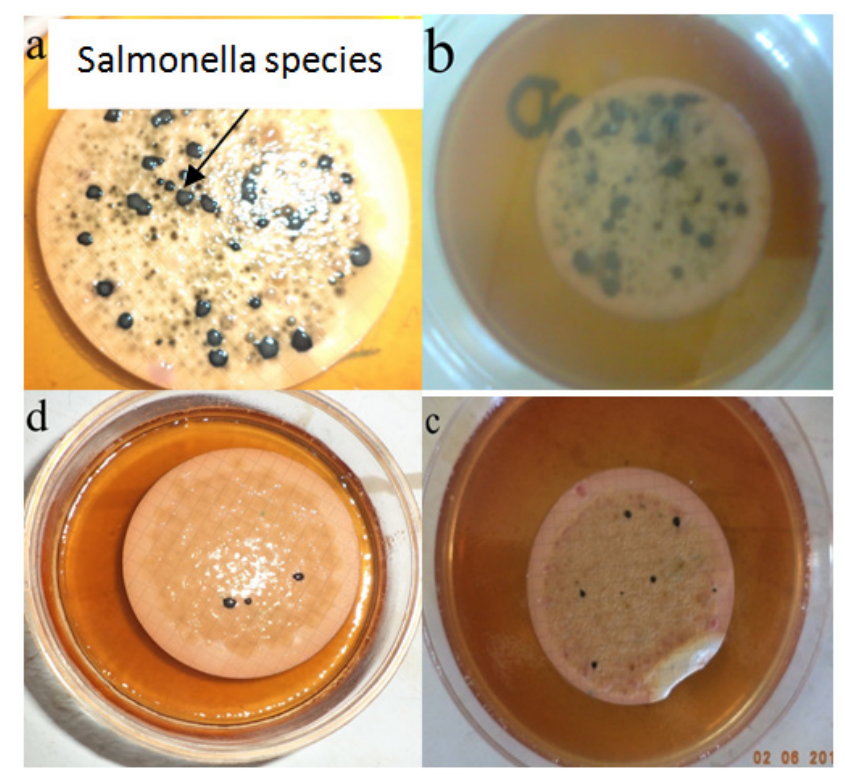

Plate 2. Salmonella species densities (black colonies) after 6 hours of exposure: a) without magnetic field; b) magnetic field of $2 \mathrm{mT}$; c) magnetic field of $6 \mathrm{mT}$ and, d) magnetic field of $10 \mathrm{mT}$
Increasing the time of exposure to 18 hours led to a slightly different trend in the number of colonies formed by the different strengths of the magnetic fields used.

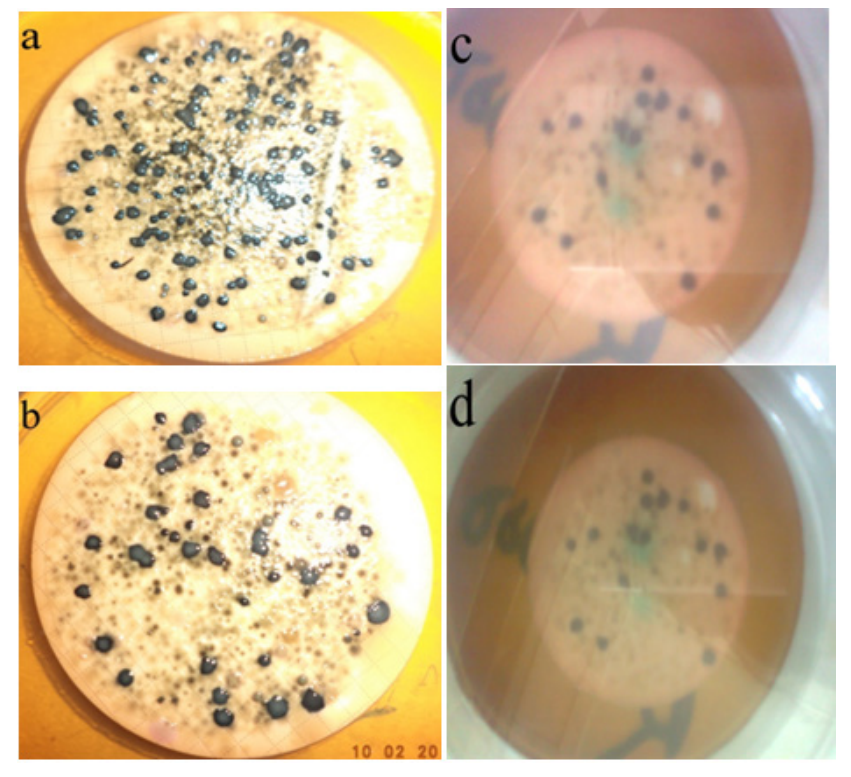

Plate 3. Salmonella Species densities (black colonies) after 18 hours of exposure: a) without magnetic field; b) magnetic field of $2 \mathrm{mT}$; c) magnetic field of $6 \mathrm{mT}$ and, d) magnetic field of $10 \mathrm{mT}$

From the present data it can be easily deduced that MFD has bactericidal effects on the density of Salmonella species in water after 6 hours of exposure and with increasing strength of the field. The highest mean number of Salmonella species was recorded with the control. Magnetic flux of $2 \mathrm{mT}$ gave a mean number of 16.25 $\mathrm{cfu} / 100 \mathrm{ml}$, $6 \mathrm{mT}$ decreased the number further to 9.75 $\mathrm{cfu} / 100 \mathrm{ml}$ and $10 \mathrm{mT}$ recorded the least mean number of $4.25 \mathrm{cfu} / 100 \mathrm{ml}$. Plate 3 shows that increasing the time of exposure to 18 hours caused slight decrease in the mean number of the Salmonella species as compared to the control. Magnetic fields of $2 \mathrm{mT}, 6 \mathrm{mT}$ and $10 \mathrm{mT}$ decreased the mean number of Salmonella species to $14.5,11.75$ and $13.75 \mathrm{cfu} / 100 \mathrm{ml}$ respectively. This is shown in Table 1 , Figure 2 and Figure 3.

Figure 4 and Figure 5 shows the percentage decrease of Salmonella species as a function of the strength of the magnetic field after 6 and 18 hours of exposure respectively. It is clear from Figure 4 that for the exposure period of 6 hours, an increase in the strength of the magnetic field caused a remarkable decrease in the mean percentage of the Salmonella species as compared to the control. However, at the exposure period of 18 hours, there was a very slight decrease in the mean percentage of the Salmonella species with a stimulation case at a magnetic flux density of $10 \mathrm{mT}$ This is similar with Mohammed et al [16] who reported that exposing S. typhi to a $20 \mathrm{G}$ magnetic field increased their cell division and cell number. This is shown in Figure 5.

The results in Figure 6 indicate considerable changes in the percentage mean density of Salmonella species for the two exposure periods 6 hours and 18 hours. For the exposure period of 6 hours, maximum percentage decrease (77\%) occurred at a magnetic field strength of $10 \mathrm{mT}$. Increasing the exposure period to 18 hours caused a different trend in the density of the Salmonella species. It 
is possible that MFD has a short period inhibition of Salmonella Species. This shows that the electromagnetic field was used either to inhibit or to stimulate the growth of the microorganism under appropriate conditions. For this case the exposure period of 6 hours shows an inhibition case while that of 18 hours shows a stimulation case. This could be as a result of the external magnetic field strength being very large relative to the bio magnetic field of the cells which causes a disturbance in their metabolic function.

The fact that MFD could inhibit Salmonella Species growth is quite promising as a potential technique for disinfecting water contaminated with Salmonella Species. Moreover, the relevance of the findings is strongly supported by the fact that Salmonella species are quite heterogeneous and the said genera is an assembly of over
2600 serotypes. Further the infective dose of Salmonella typhi the most pathogenic species is 107 cells/ml [17].

Table 1. Effect of different strengths of MFD on Salmonella species numbers (CFU/100ml) after $6 \mathrm{hrs}$ and $18 \mathrm{hrs}$ of exposure (average \pm standard deviation)

\begin{tabular}{lll}
\hline Time of exposure & MFD & Mean \pm Std. Dev \\
\hline $6 \mathrm{Hrs}$ & control & $18.50 \pm 6.19$ \\
& $2 \mathrm{mT}$ & $16.25 \pm 6.70$ \\
& $6 \mathrm{mT}$ & $9.750 \pm 4.65$ \\
& $10 \mathrm{mT}$ & $4.250 \pm 2.99$ \\
\hline $18 \mathrm{Hrs}$ & control & $18.25 \pm 6.13$ \\
& $2 \mathrm{mT}$ & $14.50 \pm 4.93$ \\
& $6 \mathrm{mT}$ & $11.75 \pm 2.94$ \\
& $10 \mathrm{mT}$ & $13.75 \pm 1.73$ \\
\hline
\end{tabular}

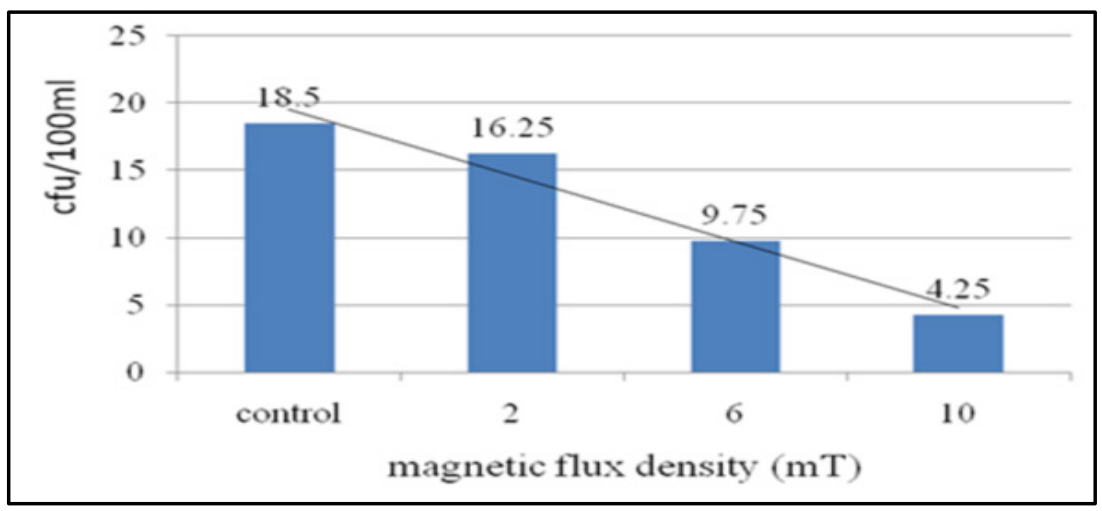

Figure 2. Mean densities of Salmonella species $(\mathrm{cfu} / 100 \mathrm{ml})$ due to different strengths of MFD after 6 hours of exposure

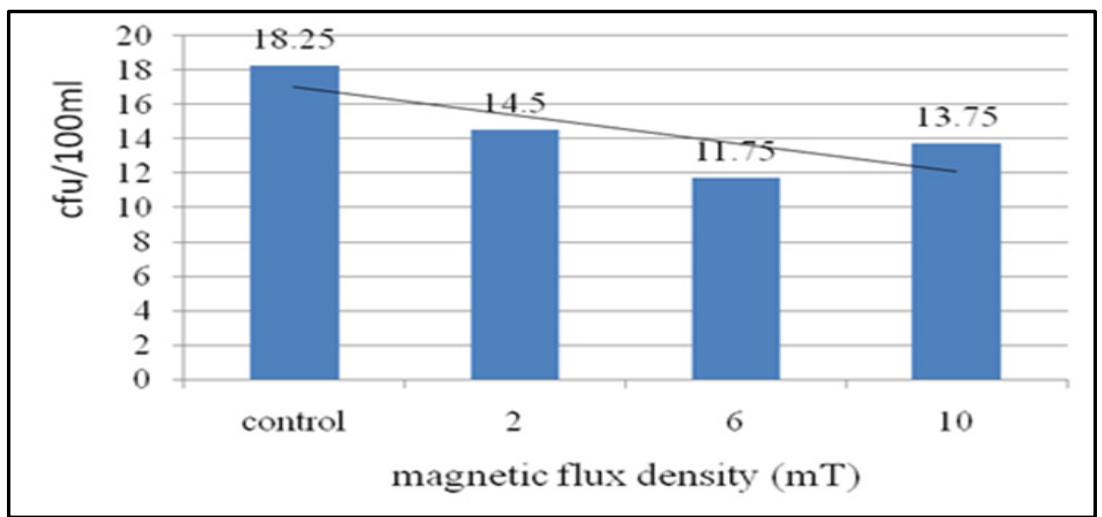

Figure 3. Mean densities of Salmonella species (cfu/100ml) due to different strengths of MFD after 18 hours of exposure

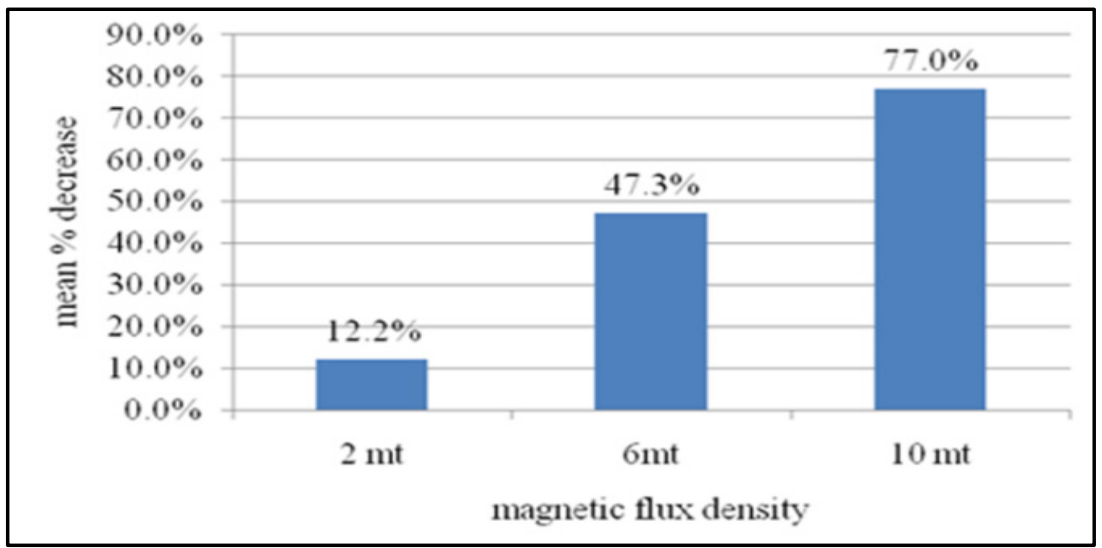

Figure 4. Percentage decrease in the mean number of Salmonella species in water after 6 hours of exposure to different intensities of MFD (2 mT, 6 mT and $10 \mathrm{mT}$ ) 


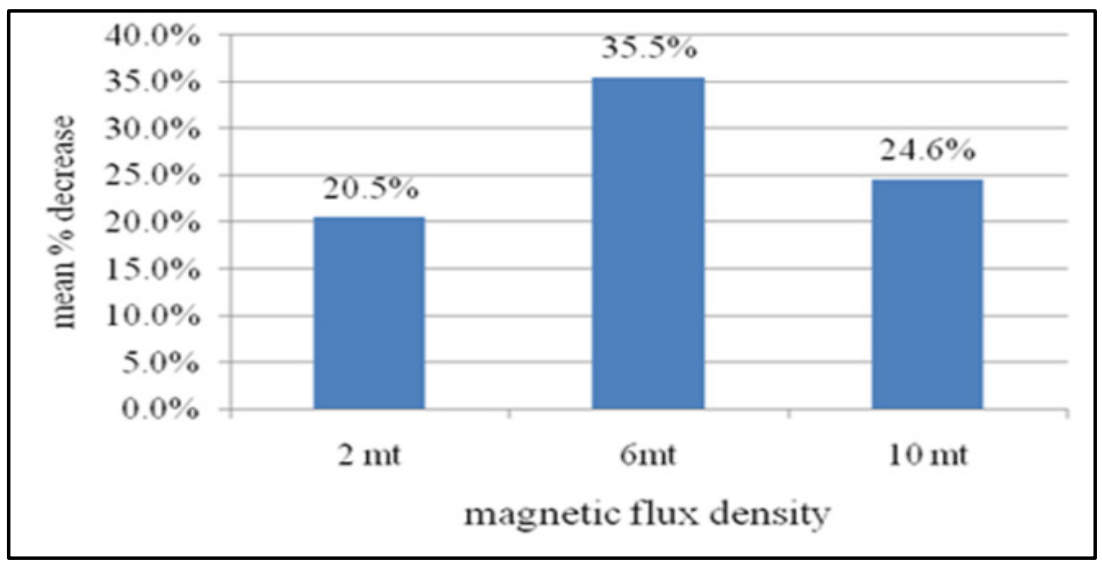

Figure 5. Percentage decrease in the mean number of Salmonella species in water after 18 hours of exposure to different intensities of MFD ( 2 mT, 6 $\mathrm{mT}$ and $10 \mathrm{mT}$ )

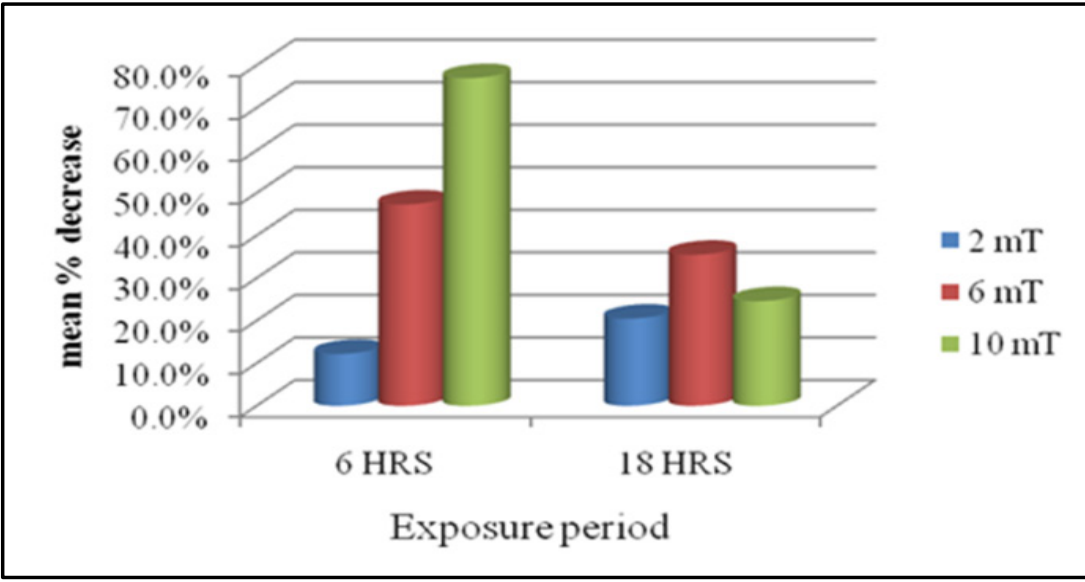

Figure 6. Percentage decrease in the number Salmonella species (cfu/100ml) in river Njoro water after 6 hours and 18 hours of exposure to different intensities magnetic flux density

Table 2. Correlation between MFD (mT) and mean number of Salmonella species (cfu/100ml) after 6 hours of exposure

\begin{tabular}{|c|c|c|c|}
\hline & & Magnetic Flux Density & Mean number of Salmonella Species \\
\hline \multirow{3}{*}{ Magnetic Flux Density } & Pearson Correlation & 1 & $-.999(* *)$ \\
\hline & Sig. (2-tailed) & . & .001 \\
\hline & $\mathrm{N}$ & 4 & 4 \\
\hline \multirow{3}{*}{ Mean number of Salmonella Species } & Pearson Correlation & $-.999(* *)$ & 1 \\
\hline & Sig. (2-tailed) & .001 & . \\
\hline & $\mathrm{N}$ & 4 & 4 \\
\hline
\end{tabular}

** Correlation is significant at the 0.01 level (2-tailed).

Table 3. Correlation between MFD (mT) and mean number of Salmonella species (cfu/100ml) after 18 hours of exposure

\begin{tabular}{clcc}
\hline & & Magnetic Flux Density & Mean number of Salmonella Species \\
\hline \multirow{2}{*}{ Magnetic Flux Density } & Pearson Correlation & 1 & $-.995(* *)$ \\
& Sig. (2-tailed) &. & .005 \\
& $\mathrm{~N}$ & 4 & 4 \\
& Pearson Correlation & $-.995(* *)$ & 1 \\
Mean number of Salmonella Species & Sig. (2-tailed) & .005 & 4 \\
& $\mathrm{~N}$ & 4 & 4 \\
\hline
\end{tabular}

** Correlation is significant at the 0.01 level (2-tailed).

Correlation analysis demonstrated that MFD was negatively significantly correlated with mean number of CFU ( $\mathrm{r}=-.999$, $\mathrm{p}<0.05)$ and $(\mathrm{r}=-995, \mathrm{p}<0.05)$ for 6hours and 18hours of exposure respectively as shown in Table 2 and Table 3.

\section{Conclusion and Recommendation}

Based on the findings of this study, the following conclusions can be drawn that the maximum disinfection 
efficiency was $77 \%$ for Salmonella species exposed to $10 \mathrm{mT}$ of magnetic flux density for a period of 6 hours.

Arising from the findings of this study, further research on the following areas concerns has to be done:

1. A study to show how long the inhibitory effects of magnetic field lasts in the treated water after withdrawing the field.

2. Investigation of effect of different intensities of magnetic field on heavy metals in water

\section{References}

[1] Human Development Report 2010. 20th Anniversary Edition. The Real Wealth of Nations: Pathways to Human Development http://hdr.undp.org/en/reports/global/hdr, UNDP 2010. Accessed on $2012 / 8 / 3,1626 \mathrm{hrs}$.

[2] World Health Report 2012. W H O http://www.who.int/rpc/whr2012/en/index.html; accessed on 2012/8/3, 1614hrs

[3] World Health Statistics 2011. http://www.who.int/whosis/whostat/2011/en/index.html, W H O 2011. Accessed on 2012/8/3, 1626hrs

[4] World Water Assessment Programme, (2006), Kenya National Water Development Report. Case study. In UN-Water/WWAP/2006/12.

[5] Kiruki S. et.al. Bacteriological quality and diarrhoeagenic pathogens on River Njoro and Nakuru Municipal water, Kenya. International Journal for Biotechnology and Molecular Biology Research, 2: $150-162,2011$

[6] Kronenberg K., "Experimental evidence for the effects of magnetic fields on moving water". Institute of Electrical and
Electronics Engineers Transactions on Magnetics, 21: 2059-2066, 1985.

[7] Lin I.J. and Yotvat J., Exposure of irrigation and drinking water to a magnetic field with controlled power and direction. Journal of Magnetism and Magnetic Materials, 83: 525-526, 1990.

[8] Balcavage W.X. et. al, A mechanism for action of extremely low frequency electromagnetic fields on biological systems. Biochemical and Biophysical Research Communication, 222: 374-378, 1996.

[9] Molouk M.K.A. and Amna A.N.S, The effect of magnetic field on the physical, chemical and microbiological properties of the lake water in Saudi Arabia. Journal of Evolutionary Biology Research 2: 7-14, 2010

[10] Smothers K.W, et. al. Water Treatment. Public Works Technical Bulletin, 420:34-449, 2001.

[11] Szkatula A, et. al. Magnetic treatment of industrial water. Silica activation. The European Physical Journal Applied Physics, 18: 41, 2002.

[12] Murimi, Shadrack Kiana. Environmental impact assessment of soil and water resources in the watershed of Lake Nakuru. Kenyatta University. 2012.

[13] Neill M. Microbiological indices for total coli form and E. coli bacteria in estuarine waters. Marine Pollution Bulletin, 49: 752-760, 2004.

[14] APHA., Standard Methods for the Examination of water and Wastewater, 25th edition. American Public Health Association/ American Water Works Association/ Food safety and Inspection Services: Washington, DC, 2008.

[15] USDA-FSIS, Most probable number procedures and tables: Laboratory Guide Book. pp. 5-8, 2008.

[16] Mohamed A.A. et. al. Effect of magnetic field on the biophysical, biochemical properties and biological activity of Salmonella typhi, Master Thesis Submitted for Biophysics Department, Faculty of Science, Cairo University, Egypt. pp: 12-35, 1997.

[17] USEPA. Current drinking water standards. United States Environmental Protection Agency: Washington, DC, 2003. 